\title{
Entre Arendt y Zerilli: algunas observaciones sobre el concepto de entre
}

\author{
Between Arendt and Zerilli: \\ some observations about the concept of in-between
}

EDGAR STRAEHLE*

\begin{abstract}
Resumen: Este artículo comenta la importancia creciente que posee una categoría como la de espacio para comprender mejor la historia política, especialmente la de las mujeres, y analiza el pensamiento de Hannah Arendt desde una óptica espacial para ver cómo su concepción de la política gravita en gran medida sobre conceptos como los de mundo y entre. Asimismo se examina la lectura que Linda Zerilli hace de Arendt para mostrar cómo sus reflexiones pueden ser provechosas para una práctica del feminismo fundada sobre todo en la idea de libertad y en la construcción-de-mundo. Palabras clave: Entre, Hannah Arendt, Linda Zerilli, Mundo común, Espacio, Feminismo.
\end{abstract}

\begin{abstract}
This article highlights the growing importance of space as a category to better understand the political history, especially the history of women. After that this article analyzes the philosophy of Hannah Arendt from a spatial point of view in order to show how her understanding of politics is based to a considerable extent on concepts, such as common world and in-between. Finally it will be examined Zerilli's reading of Arendt in order to show how her thoughts can be really useful for a feminism based on freedom and world-building.

Key Words: In-between, Hannah Arendt, Linda Zerilli, common world, Space, Feminism.
\end{abstract}

El mundo está entre las personas, y este estar-entre -mucho más que los seres humanos o incluso el ser humano, como a menudo se piensa-es hoy la causa de la mayor preocupación y de la sacudida más obvia en casi todos los países del planeta»

(Arendt, 1990, 14).

«Lo específicamente humano de la vida humana es que se construye un mundo»

(Arendt, 2006, 355).

Fecha de recepción: 30/05/2014. Fecha de aceptación: 22/11/2014.

* Investigador predoctoral del Seminario Filosofia i Gènere de la Universitat de Barcelona. Líneas de Investigación: el pensamiento de Hannah Arendt; el concepto de autoridad; la relación entre el espacio y la política; nuevos movimientos políticos. Publicaciones recientes: «El judío Süss y el cine antisemita del Tercer Reich: una aproximación a los límites del poder totalitario». Ápeiron. Estudios de filosofía, n 1, 2014 e «Insolencia y política: anotaciones acerca de una relación olvidada». Oxímora. Revista Internacional de Ética y Política, $\mathrm{n}^{\circ}$ 3, 2013. El presente artículo se ha realizado dentro del marco del proyecto de investigación "Filósofas del siglo XX: Maestros vínculos y divergencias" (FFI2012-30465) y del GRC "Creació i pensament de les dones" (2014 SGR 44). La investigación ha podido llevarse a cabo gracias al apoyo de la Secretaria d'Universitats i Recerca del departament d'Economia i Coneixement de la Generalitat de Catalunya (2013FI_B 01083). Agradezco a Ana Lanfranconi su lectura y sus consideraciones. Contacto: edgarstraehle@gmail.com. 
En los últimos lustros una categoría como la de espacio ha cobrado una mayor presencia en el debate intelectual. Uno de los protagonistas más relevantes de esta recuperación ha sido sin duda el geógrafo Edward Soja, quien denunció que las reflexiones acerca del tiempo habían absorbido las correspondientes al espacio y acuñó la expresión spatial turn para bautizar a este conjunto heteróclito de pensadores que habrían conseguido restaurar la dignidad propia de una dimensión como la espacial. De lo que se trataba, especialmente por lo que concierne a Edward Soja (1989), era de reivindicar que el espacio no era ni mucho menos un elemento neutro o eminentemente pasivo sino que, atravesado por múltiples tensiones y desigualdades, también intervenía activamente como un factor muy a tener en cuenta en la historia. Con todo, en un principio no se prestó una especial atención a cómo la cuestión del género incidía de manera notoria y decisiva en la configuración del espacio. Así que gracias a las pertinentes y necesarias críticas de geógrafas como Doreen Massey, reproches aceptados por Edward Soja e integrados en sus escritos posteriores, la misma idea de espacio habría ganado riqueza y fidelidad a la realidad al conceder más importancia a la perspectiva de género.

El espacio ha sido sin duda una categoría central en el ámbito de la política, y una categoría donde la cuestión sexual ha jugado un rol destacado, como se muestra por los reiterados intentos de expulsar a las mujeres del espacio público o, en su defecto, también por el hecho de que hablar de mujeres públicas significaba conminarlas o asociarlas a la prostitución. Se quiso recluir a las mujeres en el recinto de lo privado, por lo que se las privaba de la esfera pública y a la vez se privaba a la sociedad de su presencia (o de los peligros que ellas pudieran originar), lo que permitía y garantizaba la permanencia de la hegemonía patriarcal en el seno de la cultura. Y para colmo, a menudo se recurría a presuntos elogios que catalogaban a la mujer como el ángel del hogar o la guardiana de la virtud, de una virtud desligada de su etimología (asociada al vir y a la virilidad) y que para ser reconocida como tal debía caracterizarse por su inocuidad o, mejor aún, por su invisibilidad o mutismo en la esfera política. A saber, una suerte de proceso de infantilización, recordando que infans originalmente no quería decir otra cosa que aquel que no tiene la capacidad de hablar.

Durante la Revolución Francesa, por ejemplo, fue justamente el gobierno jacobino el que decidió clausurar los clubes políticos femeninos sirviéndose en buena medida de la mala reputación de María Antonieta y de Charlotte Corday (la asesina de Marat) para condenar a las mujeres por entero, de modo que se llegó a señalar que el deber de una republicana consistía en permanecer en el hogar. Es decir, lo que debía defender una mujer con convicciones políticas asociadas a un ideal de res publica consistía básicamente en un enclaustramiento (eso sí presuntamente republicano) a su res privata (vid. Fraisse, 2003). El diputado jacobino Jean-Pierre-André Amar no lo pudo expresar de manera más diáfana al pronunciar uno de los discursos que contribuyó a la clausura de esos clubes y proclamar lo siguiente:

«¿Deben reunirse las mujeres en asociaciones políticas? (...) ¿Pueden las mujeres dedicarse a funciones tan útiles como áridas? Por supuesto, no, porque se verían en la obligación de descuidar quehaceres más importantes a los que la Naturaleza las ha destinado. Las funciones privadas a las cuales están abocadas las mujeres, por propia naturaleza, hacen parte del orden general de la sociedad; ese orden social es consecuencia de la diferencia existente entre el hombre y la mujer. Cada sexo está 
llamado a desempeñar una función que le es propia; su acción queda circunscrita en ese círculo cuyos límites no puede franquear, pues la Naturaleza, que ha impuesto esas limitaciones al hombre, manda de manera soberana y no acepta ley alguna» (citado por Duhet, 1974, 152).

Un ejemplo más polémico y radical todavía fue el de Sylvain Maréchal, sintomáticamente un seguidor de Babeuf y autor del Manifiesto de los Iguales, quien en 1801 llegó a redactar el «Proyecto de una ley que prohíbe leer a las mujeres», en el cual además sugería que se les prohibiese pintar, hacer solfeo, imprimir... (vid. Fraisse, 1989).

Por todo ello, repensar de nuevo el espacio, cuanto menos para reconocer y recordar que no es en absoluto neutro, no deja de ser una tarea que nunca debería ser abandonada. Suele suceder, sin embargo, que redescubrir la importancia de un concepto echado en falta en el pensamiento conduce asimismo a redescubrir, o revalorizar, reflexiones que determinados filósofos y filósofas habían realizado ya anteriormente en esa misma línea. Como es natural, una categoría tan importante como la de espacio pudo haber quedado postergada por culpa de la gran importancia atribuida al tiempo, como así lo ha denunciado Edward Soja, pero ni mucho menos eso implica que haya quedado del todo desapercibida o desatendida.

Al menos este diagnóstico cuadra perfectamente con las aportaciones de una pensadora como Hannah Arendt, quien pese a haber focalizado buena parte de sus escritos en torno a un tema como el de la tradición (así como en el de su ruptura), es difícil de olvidar que nociones suyas como las de mundo o entre ocupan un rol no sólo nada desdeñable sino central en su pensamiento. Y por cierto, no precisamente como un espacio insustancial o descualificado, puramente neutro. De hecho, se podría afirmar que uno de los objetivos del pensamiento de Arendt consistiría en restaurar o cultivar con mayor vigor un espacio de la política, lo que justificaría el bello título del estudio que Cristina Sánchez (2003) le ha dedicado a la pensadora alemana.

\section{Arendt y el mundo}

Hablar del espacio y de otros conceptos afines (sobre todo los ya mencionados de mundo y entre) en Hannah Arendt se antoja una tarea compleja, especialmente dentro de las dimensiones inherentes a un artículo, y no está exenta de ambigüedades e incluso contradicciones, en buena parte a raíz de esa forma suya de pensar, tan dispersa y poco sistemática, razón por la cual fue calificada de manera acertada como un pensar sin barandillas (ohne Geländer o without a bannister). Y esto entronca asimismo con el hecho de que, como ella misma explicitó, siempre empezaba a pensar como si nadie hubiera pensado antes (Arendt, 1995, 170). Con todo, es posible aseverar que sus múltiples reflexiones aparecen en realidad como un conjunto de variaciones o modulaciones en torno a una serie de cuestiones clave, inevitablemente discordantes hasta cierto punto en un pensamiento que se mantiene abierto y a la escucha de los acontecimientos, pero que quizá, como ha sostenido Simona Forti (2001, 134), a la hora de la verdad es posible que no conlleven cambios del todo sustanciales en el interior del recorrido del pensamiento de la autora alemana.

Además, pese a que el recurso a la vida personal no siempre sea enriquecedor, y a menudo no sirva más que para ocluir una cuestión filosófica o disolverla en una biográfica, no pode- 
mos dejar de señalar que la cuestión del mundo, o mejor dicho, la de su sustracción o pérdida, enlaza con su trayectoria vital. Hannah Arendt, por culpa de sus raíces judías, tuvo que padecer una condición de paria y de paria consciente, por usar una expresión de Bernard Lazare que ella empleó en sus reflexiones (vid. Arendt, 2004), por lo que finalmente tuvo que dejar su país e ir al exilio, convirtiéndose en una refugiada. Para colmo, también acabó por ser marginada y demonizada en numerosos círculos judíos, como los sionistas, sobre todo por la polémica que desencadenó el caso Eichmann, si bien escritos suyos anteriores (tales como Sionismo reconsiderado) ya le granjearon tanto críticas severas como animadversiones personales.

Un estudio del espacio en Hannah Arendt nos remonta como mínimo ${ }^{1}$ a la que fue su primera gran obra publicada, Los orígenes del totalitarismo. En este texto se observa que el espacio público comparece como aquello que es negado pertinaz u obsesivamente por el totalitarismo, tanto por medio de leyes que proscriben un uso libre de los lugares públicos como por una propaganda cuya fuerza «descansa en su capacidad de aislar a las masas del mundo real» (Arendt, 2009, 618-619). Por decirlo sucintamente, el totalitarismo se habría caracterizado, y en ello se fundaba en gran medida la razón de su éxito, por conseguir cercenar la relación de las personas con el mundo, para lo cual no tenía reparos en atentar contra la verosimilitud e incluso arrojar acusaciones manifiesta o descaradamente falsas, por muy absurdas que éstas fueran. De hecho, una de las perversidades del totalitarismo se plasmaría en su total despreocupación por el auténtico contenido de la realidad, puesto que «no se contentaba con mentir, sino que deliberadamente se proponía transformar sus mentiras en realidad» (Arendt, 2005a, 182).

Pese a sus constantes y encendidas loas a la comunidad y a la idea de Volk, el gobierno nacionalsocialista habría conseguido depositar a los alemanes en un profundo aislamiento (isolation), lo que para Arendt constituye el comienzo y el más fértil terreno del terror (Arendt, 2009, 796). Y este aislamiento, promovido por campañas donde todo conato de diferencia era asimilado con extrema facilidad a la traición, habría sido uno de los mecanismos privilegiados para conseguir este comentado proceso de supresión de la realidad. Y a su vez habría alimentado o intensificado, entre otras cosas en virtud de un sistema de delación generalizada, un círculo vicioso de mayor desinformación y a la larga de mayor dependencia hacia el régimen hitleriano.

No es éste el lugar para examinar pormenorizadamente la concepción que Hannah Arendt aporta del totalitarismo, puesto que lo que nos interesa es constatar cómo el análisis de éste sirve asimismo para introducirnos en la problemática del mundo. Así se desprende de uno de los pasajes centrales del libro:

«El totalitarismo busca no la dominación despótica sobre los hombres, sino un sistema en el que los hombres sean superfluos. El poder total sólo puede ser logrado y salvaguardado en un mundo de reflejos condicionados, de marionetas sin el más ligero rasgo de espontaneidad. Precisamente porque los recursos del hombre son tan grandes puede ser completamente dominado sólo cuando se convierte en un espécimen de la especie animal hombre» (Arendt, 2009, 763-764).

1 Y decimos como mínimo porque en la misma tesis doctoral de Hannah Arendt, El concepto de amor en San Agustín, la concepción del mundo despliega cierta entidad propia (vid. por ejemplo Arendt, 2001, 33). 
La superfluidad de los hombres anhelada y perseguida por el totalitarismo no sólo se mostraría en el hecho de su fácil e impune sacrificabilidad, sino también en la eliminación de cualquier adarme de una espontaneidad que a la postre pudiera poner en peligro la estabilidad y permanencia del régimen totalitario. Por consiguiente, y esto es lo que nos proponemos remarcar en estas líneas, la finalidad consistiría en despojar a las personas de su potencial político y asemejarlas a las marionetas mencionadas, con el objeto de erradicar los rastros o las muestras de individualidad en las personas y, desde luego, imposibilitando cualquiera de sus posibles manifestaciones divergentes en el espacio público. Es éste el sentido que transmite esa frase en la que la pensadora alemana indica que «ser superfluo significa no pertenecer en absoluto al mundo» (Arendt, 2009, 800). Bajo el totalitarismo, uno no pertenece al mundo porque por medio del aislamiento y del terror el mismo mundo le ha sido denegado a uno mismo. Uno pierde el mundo pero asimismo el mundo lo pierde a él.

En otras palabras, el totalitarismo atentaría directamente contra la existencia de un espacio intermedio o entre, y eso no sucede tan sólo por medio de la prohibición a acceder a espacios públicos o de socialización sino por el denodado intento de buscar que esas personas no tengan nada que decir ni tampoco, por los riesgos que entrañaría, ganas o la voluntad de decirlo. Por lo tanto, una política en contra del entre no sería tan sólo meramente espacial, dado que se dirigiría a su vez a conseguir que las conciencias de hombres y mujeres fuesen de veras superfluas y redundantes, desprovistas de diferencia u oposición; donde, a efectos políticos, uno no fuese más que un simple e intrascendente trasunto de los demás.

Con esto se entiende el siguiente pasaje de Ideología y terror, ese capítulo que Arendt añadió más adelante a Los orígenes del totalitarismo, y donde la cuestión del espacio cobra una mayor presencia:

«Presionando a los hombres unos contra otros, el terror total destruye el espacio entre ellos; en comparación con las condiciones existentes dentro de su anillo de hierro, incluso el desierto de la tiranía parece como una garantía de libertad en cuanto que todavía supone algún tipo de espacio (...). Destruye el único prerrequisito esencial de todas las libertades, que es simplemente la capacidad de movimiento, que no puede existir sin espacio» (Arendt, 2009, 782).

El totalitarismo se revela pues como el régimen que con mayor crudeza ha atentado contra la idea de espacio y que, no satisfecho con liquidar o desertizar cualquier tipo de espacio público, acude a la misma fuente de la libertad para neutralizarla, procurando laminar también la misma vida privada e incluso forjar una nueva naturaleza humana (Arendt, 2009, 799). Aunque por eso mismo el análisis del totalitarismo sirve de paso para apreciar el valor que intrínsecamente contiene la dimensión espacial. Ideología y terror, quizá por eso, combina el estudio del terror totalitario con la presentación de otros de los temas o conceptos clave que recorrerán las obras futuras de Hannah Arendt, tales como la acción o esa concepción de la libertad que ya en aquel entonces asocia al nacimiento $\mathrm{y}$ al poder comenzar. 
Ideología y terror es un escrito que sirve de enlace entre Los orígenes del totalitarismo y La condición humana, ${ }^{2}$ obra escrita explícitamente contra la condición del mundo moderno (Arendt, 1993, 18). En este texto late una inquietud semejante que sin embargo anida en un contexto radicalmente distinto. La inquietud por la pérdida del mundo ya no se restringe al totalitarismo y se apunta ahora contra la misma condición moderna. El ensayo profundiza en el declive de lo político, invadido, absorbido o sustituido por lo social, y Arendt denuncia asimismo que se haya impuesto un ideal de vita activa vaciado de su potencial político, más enfocado a una realización privada, y que la acción haya quedado relegada por culpa del creciente auge de la conducta (behaviour), mediante la imposición de normas que tienden a la normalización de las personas y a excluir la acción espontánea. La dureza de su diagnóstico se plasma en su rotundidad cuando al final de la obra llega a aseverar que «resulta fácilmente concebible que la Época Moderna (...) acabe en la pasividad más mortal y estéril de todas las conocidas por la historia» (Arendt, 1993, 346).

La consecuencia obvia de lo anterior consiste en una pérdida de mundo (Worldlessness o Weltlosigkeit) análoga a la producida por el totalitarismo, si bien por unas razones y con unos resultados harto diferentes. Ya no viene originada por una política del terror sino por el advenimiento de lo social que conduce a una alienación del mundo, que separa al hombre de éste y que lleva a la exclusión de la acción espontánea o del logro sobresaliente; que reduce a los miembros de la sociedad a los automatismos de la marea de la conducta o del comportamiento. O también donde la misma palabra «interés», que antaño hacía alusión al inter esse que se sitúa en medio de las personas, se individualiza y deja de hacer referencia a algo común o compartido. Y por eso mismo, tal como lo expresa Hannah Arendt, «lo que hace tan difícil de soportar a la sociedad de masas no es el número de personas, o al menos no de manera fundamental, sino el hecho de que entre ellas el mundo ha perdido su poder para agruparlas, relacionarlas y separarlas.» (Arendt, 1993, 62). El espacio público queda eclipsado y deviene un lugar intrascendente, donde no hay interacción y donde por tanto no hay propiamente mundo; o por decirlo en términos actuales, se descubre como un sitio que se caracteriza por lo que algunos llaman interpasividad (vid. Zizek, 2007). Es decir, un terreno donde el amontonamiento de personas indica de manera fehaciente que el número no hace sino certificar y agravar la problemática de la ausencia de mundo.

El mundo, en cuanto es común a todos nosotros, no es idéntico a la Tierra o a la Naturaleza, no es algo que esté ahí, como una entidad autosubsistente, al margen de lo que se diga o haga. Arendt lo concibe como una construcción realizada y preservada por los hombres, hecha a partir de objetos fabricados, acciones y, por tanto, también discursos. El mundo lo es en la medida en que es plural, en que se caracteriza por una pluralidad real y efectiva de personas. «Sólo hay mundo en el sentido auténtico del término donde la pluralidad del género humano es algo más que la multiplicación de ejemplares de una especie» (Arendt, 1997a, 118). El mundo existe en virtud de la presencia de los demás, de que haya otros que ven lo que vemos y oyen lo que oímos, lo que nos asegura la realidad del mundo y al fin y al cabo de nosotros mismos. Y por eso mismo debe ser un espacio que tenga la capacidad

2 Aquí suscribimos la opinión de Margaret Canovan (1992), quien al contrario que otros comentadores como George Kateb o Bikhu Parekh, ha destacado la importancia de Los Orígenes del Totalitarismo para comprender el resto de la obra de Hannah Arendt. 
de congregar efectiva y, en la medida de lo posible, también dilatadamente una multiplicidad de perspectivas. «Al igual que la mesa está localizada entre los que se sientan alrededor; el mundo, como todo lo que está en medio, une y separa a los hombres al mismo tiempo» (Arendt, 1993, 61-62). Lo importante del mundo consiste en que une y separa y que por el mismo hecho de conducirnos hacia el otro también nos aleja de él; por eso, podríamos decir asimismo que en verdad separa precisamente porque une. No se trata, desde luego, de una unión en la que uno deba someterse o subordinarse a una identidad o un patrón común, dado que se revela como un terreno de interacción que es posible precisamente en virtud de la conjunción simultánea de la identidad y de la diferencia.

En efecto, esa pluralidad se da porque ella manifiesta el doble carácter de la igualdad y la distinción. «Si los hombres no fueran iguales, no podrían entenderse ni planear y prever para el futuro las necesidades de los que llegarán después. Si los hombres no fueran distintos, es decir, cada ser humano diferenciado de cualquier otro que exista, haya existido o existirá, no necesitarían el discurso ni la acción para entenderse» (Arendt, 1993, 200). Es este doble rasgo de igualdad y distinción, o de distinción en la igualdad, lo que permite esa situación de separación dentro de la unión y lo que sintetiza lo que es el entre. Solamente así se posibilita y fragua la existencia y la coexistencia de la pluralidad, de un mundo común que se constituye y configura gracias a la simultánea presencia de distinciones siempre que éstas no sean vistas como una simple pero radical alteridad (otherness), una diferencia como la presente en los objetos inorgánicos, sin posibilidad de interacción ni de desvelar nada.

En el discurso y en la acción, y para Arendt no hay acción sin discurso, se revela la unicidad que es cada uno, su quién. Con palabras y actos nos insertamos en el mundo, lo que ella valora como un segundo nacimiento, y también lo hacemos más mundo, más plural. Se trata de un espacio de aparición donde ser y apariencia coinciden (vid. Arendt, 2002), por lo que el mundo debe ser plural por necesidad y donde una diferencia que no tenga la capacidad de escapar de la oscuridad no aparecerá en su seno y no tendrá relevancia. ${ }^{3}$ No es lo que se tiene en común sino la diferencia de cada uno lo que facilita que ellos puedan relacionarse o unirse (vid. Birulés, 2014, 40), y sin embargo lo que de todos modos y de manera inevitable lo fragiliza.

El mundo se nos manifiesta como una trama o una red (web) de diferencias que se entrecruzan y que por eso pueden desembocar en un espacio común. Uno de los aspectos fundamentales yace en que, como escribió en ¿Qué es la política?, el hombre, en sí, es apolítico pues la política nace entre los hombres, es decir, fuera de ellos (Arendt, 1997a, 46). La política, por tanto, requiere que uno salga de uno mismo, que trascienda o sobrepase el recinto de la privacidad y se exponga, acudiendo al espacio público. Y de ahí se deriva que no exista ni pueda existir una sustancia de lo político. O por expresarlo en los términos de Claude Lefort (vid. 1990): según Arendt la política se edificaría sobre el vacío, sobre un lugar imposible de ser ocupado de manera definitiva o de ser patrimonializado por alguien en concreto, de modo que lo político, en verdad, debe entenderse fundamentalmente como una dimensión relacional. Y por eso mismo, «la respuesta que sitúa al hombre en el punto central de la preocupación presente y cree deber cambiarlo para poner remedio es profundamente

3 De ahí que Arendt escriba que «una vida sin acción ni discurso (...) está literalmente muerta para el mundo; ha dejado de ser una vida humana porque ya no la viven los hombres» (Arendt, 1993, 201). 
apolítica; pues el punto central de la política es siempre la preocupación por el mundo y no por el hombre» (Arendt, 1997a, 57). La política no tiene que ver propiamente con aquello que somos en nuestro ámbito privado o con una hipotética naturaleza humana, sino con el mundo o el espacio intermedio (Zwischenraum o in-between) que se logra producir conjuntamente. Un lugar, por cierto, que no está atado a ningún espacio de aparición concreto sino que puede formarse en cualquier sitio. ${ }^{4}$

Este espacio intermedio, dada su ausencia de fundamento, se descubre como una entidad que a nivel ontológico es sumamente precaria, pero que sin embargo depende paradójicamente de su permanencia o de su estabilidad. La permanencia es lo que no se puede asegurar de ningún modo y lo que al mismo tiempo se necesita de manera imperiosa para que el mundo pueda ser y aparecer efectivamente como un mundo común. No hay mundo común sin una pluralidad que se muestre o se exponga en él, subsiste gracias a la acción conjunta de numerosas personas diferentes, por lo que cuando uno decide retirarse de su seno el mundo es menos mundo (vid. Arendt, 1990, 14-15). Y este proceso de privatización redundaría a su vez en una pérdida de la seguridad en el mundo. De ahí que la pérdida o transformación del sentido común, que de ser un sentido arraigado en la realidad y compartido con los otros pasó a convertirse en una suerte de sentido interior, corra pareja a la pérdida del mundo (vid. Arendt, 2006, 455) y también que Arendt recalque la importancia o la necesidad de la autoridad, puesto que ésta posibilita la presencia de un suelo común y porque se trata de una forma de obediencia en la que se conserva la libertad (vid. Arendt, 1988 y 1996). ${ }^{5}$

El mundo, y recordemos que Arendt quiso titular inicialmente La condición humana como Amor mundi, propicia que haya un entre que se presenta como el lugar de la libertad; al menos en la medida en que este entre se da entre iguales, por lo que la libertad emerge no como el fin sino como el mismo sentido de la política (Arendt, 1997a, 61-62). Y esta libertad, desde luego, no hace referencia al libre albedrío ni tampoco a una libertad negativa encastillada en el refugio de la privacidad, dado que se descubre como una dimensión propiamente política que se caracteriza por la espontaneidad y por el poder comenzar (anfangenkönnen). De hecho, Arendt llega a escribir que donde no hay libertad no hay política ni al

4 Arendt escribe: «La polis, propiamente hablando, no es la ciudad-estado en su situación física; es la organización de la gente tal como surge de actuar y hablar juntos, y su verdadero espacio se extiende entre las personas que viven juntas para este propósito, sin importar dónde estén. «A cualquier parte que vayas, serás una polis»: estas famosas palabras no sólo se convirtieron en el guardián fiel de la colonización griega, sino que expresaban la certeza de que la acción y el discurso crean un espacio entre los participantes que puede encontrar su propia ubicación en todo tiempo y lugar» (Arendt, 1993, 221).

5 La autoridad, a diferencia de la concepción tradicional del poder, no depende de una acción o coacción del sujeto sobre la persona objeto sino del reconocimiento que ésta le da al primero. La autoridad, invirtiendo la lógica del poder, no se la apropia uno, ya que debe ser concedida u otorgada por los demás. Por lo tanto, son los demás los que invisten de autoridad a uno, o se la quitan (de ahí que Arendt llegue a afirmar que su mayor enemigo es el desprecio e incluso la risa, vid. Arendt, 2005b, 62). Por eso, Arendt, en ese ejercicio de pensamiento que es La Crisis de la educación, explica que la autoridad facilita la introducción de los niños en el mundo y que en el fondo favorece la irrupción y la integración de la novedad. En este sentido escribe que «precisamente por el bien de lo que hay de nuevo y revolucionario en cada niño, la educación ha de ser conservadora; tiene que preservar ese elemento nuevo e introducirlo como novedad en un mundo viejo que, por muy revolucionarias que sean sus acciones, siempre es anticuado y está cerca de la ruina desde el punto de vista de la última generación» (Arendt, 1996, 204-205). Esta concepción arendtiana de autoridad ha sido reivindicada en varias ocasiones dentro del feminismo como un mecanismo de libertad y de crecimiento (vid. Librería de Mujeres de Milán, 2004; Muraro, 2013). 
revés. Ambas coinciden como dos caras de la misma moneda. Y la libertad, por eso, no se da antes o después de la acción, sino únicamente mientras se produce ésta (Arendt, 1996, 165).

La política aparece en la filosofía de Arendt como el espacio de los milagros, de lo imprevisible e incluso lo irreversible, y el entre como un lugar de emergencia de acontecimientos. Así se descubre que la política es fundamentalmente natalidad, lo que remite a esa conocida frase de San Agustín que ella repite en varias de sus obras: «para que hubiera un comienzo (initium), fue creado el hombre». Al contrario que en la fabricación, que se desenvuelve en el aislamiento y que se realiza mediante una lógica medios-fines (la cual coincide por tanto con la de la violencia y la acerca a ella), la acción se caracteriza por ser imprevisible e incluso incontrolable. ${ }^{6}$ Por eso ya no nos encontramos con autores sino con actores, los cuales no controlan los efectos que su acción desencadena (y por eso un agente es siempre y al mismo tiempo un paciente de sus actos) ni tampoco saben captar o anticipar el sentido que tendrá, lo que Arendt valora como el precio inevitable de la libertad y la razón por la que llega a definirla como la más peligrosa de «todas las habilidades y actividades humanas» (Arendt, 1996, 72).

Esta concepción de la política, y de la acción, evidencia que la relación entre teoría y praxis no debe ser conceptualizada como una relación estrictamente unidireccional, donde se le conceda a la segunda una función de simple ejecución o aplicación de la primera y por tanto subordinada a ésta. Inevitablemente, se quiera o no, se reconozca o no, la acción desborda o trasciende tanto sus motivos como sus fines. Por esa razón, Arendt critica a Platón como origen de este desgajamiento entre pensamiento y acción, el cual desemboca en la desde entonces problemática relación entre filosofía y política, donde se pasa a comprender a ésta como un modo del hacer (Arendt, 1997b). La filosofía política habría aparecido a partir de una desconfianza o rechazo del mundo, de lo que es asumido como el fracaso de la polis, el cual justificaría el alejamiento de ella. Arendt se sitúa frente a esta tradición que atraviesa la historia del pensamiento político y que sin duda no es inocente en este proceso de pérdida de mundo y de la desvalorización de éste. El mundo, como en el modelo de la fabricación, pasa a ser visto fundamentalmente como el punto final de la acción, allí donde ésta se aplica, pero no como su principio; de una acción en el fondo ya desnaturalizada, cuya función reside en no desviarse de lo planeado de antemano y que por lo tanto deviene muda y rompe con su potencial de interrupción o de fractura de lo presente.

\section{De Arendt a Zerilli}

Las relaciones entre el feminismo y el pensamiento de Hannah Arendt han estado caracterizadas por la polémica, tanto que sus escritos fueron deliberadamente ignorados durante largo tiempo. Hay que remarcar que la pensadora alemana, salvo una reseña temprana a Das Frauenproblem der Gegenwart de Alice Rühle-Gerstel (vid. Arendt, 2005a), prácticamente no afrontó ni se interesó por la cuestión del feminismo. O señalar que en su diario filosófico apuntó una frase controvertida como: «el absurdo de organizar las mujeres en cuanto muje-

6 Según Margaret Canovan (1992, 131), aquí, en esta insuprimible incertidumbre, es donde se encuentra uno de los puntos que no acaban de agradar a Hannah Arendt, razón por la que subraya la importancia del perdón y la promesa como pequeños remedios, a todas luces insuficientes, a la indomeñabilidad intrínseca a la acción. 
res. El pecado mortal es hacer pasar el méros por génos, que es un concepto racial» (Arendt, 2006, 19). Comprensibles y representativas, por eso, son las palabras citadas sin cesar de Adrienne Rich cuando afirmó que Arendt encarnaba la tragedia de una mente femenina impregnada de ideología masculina (Rich, 1983, 250). Y este rechazo generalizado perduró hasta que llegaron nuevas pensadoras que no dudaron en servirse del pensamiento de Arendt para ayudar a repensar la cuestión de género, entre las cuales podemos nombrar a Seyla Benhabib, Françoise Collin, Nancy Fraser, Julia Kristeva, Bonnie Honig, Luisa Muraro o Linda Zerilli (Guerra, 2011). Esta última ha calificado a Arendt como una socia difícil pero valiosa para el diálogo feminista y en este sentido ha indicado que «aunque nunca tuvo nada (bueno) que decir acerca del feminismo, su vehemente compromiso con una comprensión totalmente convencional, artificial o no natural del ámbito político en tanto espacio de la libertad no soberana ofrece a las feministas (...) una valiosa alternativa a los impasses asociados con la cuestión del sujeto y la cuestión social» (Zerilli, 2008, 75).

Zerilli se ha atrevido a acometer una suerte de feminización del pensamiento de Arendt para introducirla en el debate feminista que parte de la idea de mundo y que podría ser resumido como un gesto por el cual no se reduciría el universo femenino a un simple génos al introducirle la idea de méros en su seno. ${ }^{7}$ Por lo tanto, se trataría de concebir el colectivo femenino como una comunidad caracterizada por la pluralidad y por la heterogeneidad que por eso mismo debería precaverse de tentaciones (o desviaciones) por las cuales se fuese en pos de la afirmación teórica de una identidad específicamente femenina que tuviera pretensiones totalizantes.

Zerilli cuestiona fundamentalmente dos tendencias dentro del feminismo que habrían hecho caer a éste en un impasse. Para empezar, y de manera acorde a una forma de pensar arendtiana, critica una focalización excesiva en la cuestión social, porque al asimilar lo político a lo social se restringiría la acción política a una actividad de medios-fines, orientada por una lógica de la utilidad que sería ajena a su concepción de la política. Además, reprocha asimismo cierta vocación epistemológica que busca o cree poder resolver una cuestión como la del género desde una esfera en realidad extrapolítica, puesto que entonces se correría el riesgo de convertir una cuestión política en una que sería más bien cognoscitiva. En ambos casos, de hecho, se incurriría en una concepción de la política reductivista y perjudicial donde se menoscabaría el reclamo de libertad y a la larga al potencial emancipador del feminismo.

$\mathrm{Al}$ enfrentarse a las tentativas de determinar un sujeto femenino unificado, en su opinión algo tan imposible como innecesario e incluso contraproducente, ${ }^{8}$ Zerilli propone trasladar la cuestión del sujeto a la política y al espacio en el que ésta se desenvuelve. De este modo, la política no dependería del qué, el cual se podría encerrar en una definición determinada, sino del quién, que en verdad no sería uno sino que debería estar formado por una multi-

7 Uno de los aspectos más criticados a la idea de espacio político en Hannah Arendt (por ejemplo Campillo, 2002) son los límites que le colocó y que también le llevaron a afirmar que en las sociedades tribales los hombres viven juntos pero sin formar una entidad política (vid. Arendt, 1996, 160).

8 Como ejemplo paradigmático de la dificultad de cómo establecer biológicamente las fronteras de la diferencia sexual, Zerilli documenta los diferentes y contradictorios criterios que fue adoptando el Comité Olímpico, el cual en 1968 decidió pasar de la prueba de feminidad por genitales a la de cromosomas para volver en 1992 a la anterior (Zerilli, 2008, 92). 
plicidad de integrantes que no se subordinaran a un fin ni enarbolaran el estandarte de una identidad en concreto. En opinión de Zerilli, la política, y en este caso la del feminismo, debería alejarse de una concepción sustancial y aproximarse a una que sea más bien relacional, que no incurra en la afirmación de ningún absoluto. Así pues, la atención pasaría a centrarse en el mundo, en un mundo entendido de manera arendtiana, en un mundo forjado y habitado por una pluralidad real y no solamente teórica de mujeres. Y un mundo que no solamente sería un espacio de aparición o de expresión sino también de transformación. Por eso este desplazamiento comportaría asimismo un desplazamiento análogo de la esfera del saber a la del hacer.

En su opinión, el problema del feminismo, o más bien de cierto feminismo, se hallaría en sus fundamentos, en el vano intento de fijarlos de manera definitiva y de no ser capaz de encarar el «nosotras» como algo que no tiene por qué ser determinado o fijado desde fuera. En otras palabras, el quicio de este asunto se encontraría en el hecho de que se promoviera un feminismo que le sustrae su dignidad a la política y que desvirtúa lo que para ella sería más propiamente un feminismo político, razón por la que Zerilli escribe a modo de resumen: «Lo que queremos saber, en lo que atañe al feminismo, no es si la mujer/las mujeres existe(n) (por ejemplo en forma de grupo social vinculado por la experiencia compartida), sino qué significa(n) la mujer/las mujeres para aquellos que proclaman hablar políticamente en su nombre» (Zerilli, 2008, 333).

Para superar lo que denomina el encuadramiento en el sujeto Linda Zerilli aboga por una política dedicada a la práctica de construcción-de-mundo (world-building), es decir, como el cultivo de un espacio de libertad y de diferencia, como un espacio sin soberanía, que no pueda quedar clausurado o suturado por ninguna instancia externa, sea ésta una persona en particular o adopte el aspecto de un conjunto de enunciados en los que cuadrar. Y por eso mismo este espacio comparece como un mundo donde se piensa el feminismo como unas prácticas de libertad creativa o inaugural. Y sería inaugural por la capacidad que detentaría de introducir novedades y por lo tanto de quebrar cualquier intento de delimitación o apropiación de lo femenino. ${ }^{9}$

Zerilli se opone a una concepción de la libertad que la vea como una propiedad del sujeto o también a una que sea estrictamente entendida en términos de poder constituyente, suponemos que como el esgrimido por Toni Negri (1994). Tampoco acepta que sea confundida con una simple espontaneidad, puesto que se debería materializar como prácticas de construcción-de-mundo (que implican tareas como prometer, fundar y juzgar), lo que a su vez implicaría que fuese necesaria cierta estabilidad o permanencia. Citando a Arendt, Zerilli subraya que se es libre mientras se actúa, ni antes ni después, dado que ser libre y actuar son lo mismo (vid. Zerilli, 2008, 53). Y tanto libertad como acción se dan en un espacio de aparición que se mantiene vivo gracias a la idea de poder, el cual no debe ser visto como una forma de imponer una voluntad a otra persona. El poder, según la clásica definición de Arendt, lo es en la medida en que es aquello que aparece en el entre (im Zwischen) cuando los hombres actúan juntos y desaparece cuando se dispersan, de modo que no sería algo

9 Y de hecho podríamos añadir que, apelando a la etimología, también sería inaugural en la medida en que fuese algo que lo hiciese crecer o medrar, dado que el origen de la palabra inaugurar remite al verbo augere, hacer crecer. 
que un individuo tuviera la posibilidad de patrimonializar. Un individuo solitario es necesariamente impotente, nunca puede tener poder, dado que éste solamente se entiende como un actuar concertadamente, que se sustenta sobre la presencia de los otros. «El poder brota en el entre de pluralidad. En verdad nadie puede apropiárselo, pues se evapora tan pronto como se pretende trasladarlo de ese entre al "sujeto"» (Arendt, 2006, 154).

De ahí que esta exigente concepción de la libertad, de una libertad propiamente política, encaje difícilmente con una determinación extrapolítica de lo femenino. En tal caso lo político, intrínsecamente plural y por tanto indeterminable, quedaría eclipsado o heteronomizado por un elemento externo y que por tanto se condenaría sin remedio a la impotencia. Zerilli, como muestra el título de su obra más famosa, ubica el feminismo en el abismo de la libertad, el cual no sólo supone un rechazo de las pretensiones epistemológicas de hallar una solución a la cuestión del sujeto femenino, por lo que no se advertiría el carácter transformador de la práctica humana y se correría el riesgo de estar presa en una identidad determinada, sino que este abismo significaría asimismo una invitación a forjar un mundo (femenino) y, por tanto, facilitaría la articulación o el despliegue de un poder inaugural. De ahí que escriba una frase como la siguiente: «después de todo, el feminismo centrado en la libertad no se interesa en saber (que existen las mujeres) sino en hacer: en transformar, en construir el mundo, en comenzar de nuevo» (Zerilli, 2008, 137). No se trata de desprenderse de un término como el de mujer ni mucho menos, sino de comprender que su significado no viene determinado de antemano y que (afortunadamente) no puede serlo. Se trataría por lo tanto de asumir asimismo la contingencia que se esconde en su seno, aunque no en un sentido absoluto o como un rasgo propio de una actitud escéptica, sino como algo inherente al carácter rupturista y desbordante de la acción, por la cual se modifica la relación entre lo contingente y lo necesario. En efecto, para Zerilli semejante modificación

«no implica ni requiere alcanzar un punto de vista externo desde donde podríamos verlo todo como no necesario, contingente. Más bien se basa en el carácter fáctico de la libertad humana, en la capacidad de extraer algo nuevo de un estado de cosas objetivo sin tener que recurrir a una norma o una regla. En otras palabras, los cambios en el significado del género no surgen de la idea escéptica de que el género como tal es contingente y por lo tanto susceptible de ser cambiado (por ejemplo: tenemos la teoría, ahora podemos actuar), sino de la proyección de una palabra como mujeres en un nuevo contexto, donde otros la reciben en maneras que no podemos predecir ni controlar» (Zerilli, 2008, 136).

Zerilli invierte la clásica relación de prioridad y anterioridad de la teoría respecto a la práctica. Y para ello, además del rol muy importante que juega la filosofía del segundo Wittgenstein y su concepción pragmática del lenguaje, se apoya en el pensamiento de Judith Butler, fundamentalmente en el rol de la performatividad de las prácticas para la construcción del género, ${ }^{10}$ como se vería de manera ejemplar en el análisis del drag (Butler, 2007). Éste sería el ejemplo paradigmático de una fisura productiva que en su puesta en práctica

10 Es preciso recordar que la misma idea de performatividad a menudo se ha aplicado retrospectivamente para caracterizar asimismo la idea arendtiana de acción (vid. por ejemplo Honig, 1993). 
escapa y pone en cuestión la misma identidad postulada con anterioridad (Zerilli, 2008, 72). El drag, sabiéndolo o no, encarnaría por medio de su acción el momento de dislocación de la identidad y revelaría de esta manera su carácter infundado o contingente, ayudando a pensarla de un modo nuevo. Algo semejante llevaría a cabo Monique Wittig al proponer les guérrillères como una nueva figura de lo pensable.

Aunque a la perspectiva de Judith Butler le añadiría Zerilli la idea de este espacio político intermedio como el emplazamiento privilegiado para la constitución y reconstitución del colectivo de las mujeres. Las prácticas adquieren su sentido en la medida en que se dan en común y en que no consisten en una simple decisión individual o privada. Por esa razón Zerilli estudia más adelante las contribuciones realizadas por el Colectivo de la Librería de Mujeres de Milán, para quienes «estar entre mujeres es el punto de partida de nuestra política» (vid. Zerilli, 2008, 209). Este colectivo le interesa fundamentalmente como el modelo de un feminismo que prioriza la vertiente práctica, que desarrolla unas prácticas de libertad y de la diferencia sexual que se desenvuelven por lo tanto en una política del espacio femenino con interlocutoras autorizadas, lo que para ellas (tanto para Zerilli como para el colectivo de la Librería de Mujeres de Milán) tiene sentido en la medida en que se materializa en un espacio compartido de diálogo, de discrepancia y por lo tanto también de transformación (vid. Librería de Mujeres de Milán, 2004, 117).

Nos encontramos así con que, según Linda Zerilli, el principal quehacer de un feminismo político debe encaminarse a la construcción de un mundo común y que lo asume como una tarea propia de la libertad, con lo que se evidencia que una concepción negativa de ésta (que la asocie a la privacidad o a la independencia) o que la reduzca a una simple igualdad formal o de derechos, dificultaría enormemente esta tarea. Lo femenino se gesta y se redefine así gracias a unas palabras y acciones que surgen en lo común, en el entre; y que por tanto comportan la exigencia de que una salga de sí misma, de una privacidad que conlleva una privación del mundo y que en consecuencia privan también al mundo de su contribución y de su diferencia personal. La libertad debe ser una libertad real que se materializa en una acción positiva, común y potencialmente rupturista. En palabras de Zerilli, «las prácticas de libertad política tienen un carácter fundamentalmente inaugural; crean, mediante el discurso y la acción, un espacio subjetivo intermedio que revela las diferencias» y a continuación añade que en ocasiones «excede el espacio institucional de la igualdad de derechos» (Zerilli, 2008, 198).

En realidad, así ha sucedido por lo general a lo largo de la historia y Zerilli menciona como ejemplo la Declaración de Sentimientos de Seneca Falls. Con sus acciones políticas, las mujeres se han enfrentado y han subvertido infatigable y arriesgadamente los continuos intentos, amparados en los derechos vigentes, de ser encuadradas en una definición y en un quehacer concreto, lo que obviamente redundaba en su marginación política y no solamente política. Y esas acciones fueron posibles en muchos casos gracias a la gestación de espacios propiamente femeninos como espacios alternativos de reunión o como pequeños oasis de libertad, dada la imposibilidad de mostrarse o exhibirse en la esfera pública. Sintomáticamente, Christine de Pizan dibujó un proyecto hasta cierto punto semejante al de Linda Zerilli con su célebre Ciudad de las Mujeres.

La historia de las mujeres está atravesada por numerosas formas de disidencia (y por supuesto de desobediencia y resistencia), muchas de ellas lamentablemente borradas o 
desestimadas en las crónicas que nos hablan del pasado, que se ajustan a lo que James C. Scott (2000) ha denominado el espacio social del discurso oculto. ${ }^{11}$ Se trataba ciertamente de espacios heterotópicos que desde luego distaban mucho de ser ideales. De todos modos, pese a las condiciones en los que aparecían y a los peligros que entrañaban, manifestaron una gran productividad y un potencial político muchas veces minusvalorado a posteriori, lo que sin embargo el orden patriarcal sí supo captar en su momento. De ahí, como se ha comentado, esa tradicional y empecinada obsesión por expulsar a la mujer del espacio público o la decisión de los jacobinos de clausurar los clubes de mujeres poco después de que llegaran al poder.

Eso no significa, claro está, que la práctica de construcción de mundos sea suficiente para la lucha de las mujeres, por la razón evidente de que ésta se tiene que enfrentar constantemente a un Estado poco o por lo general nada proclive a ser doblegado por este tipo de reclamaciones, como también la historia nos ha mostrado en repetidas ocasiones. Por eso, la misma Linda Zerilli aboga por ejemplo por las luchas que reivindican ciertos derechos en tanto que éstos aparecen como instrumentos de libertad. El problema reside en que la institucionalización de los derechos puede conducir y conduce con frecuencia a un deterioro o un olvido de las prácticas de libertad, lo que acaba por neutralizar la conquista conseguida y el sentido que la animaba. Los derechos, al perder la conexión con las prácticas de libertad, se convertirían así en artefactos legales muertos y hasta en instrumentos políticos peligrosos (Zerilli, 2008, 231-232). En efecto, la concesión de un derecho puede derivar en una desmovilización y despolitización del colectivo que lo reclamaba. Zerilli denuncia por esa razón la orientación profundamente jurídica e institucional de gran parte del feminismo contemporáneo. No es que se manifieste en contra de sus reivindicaciones, lo que critica reside más bien en que un exceso de énfasis en este tipo de luchas acaba por olvidar el rol que debe desempeñar la libertad política en el feminismo, incluso en el caso de que se tenga éxito. Para Zerilli, «sin libertad, la igualdad de derechos se obtiene a cambio de la asimilación» (Zerilli, 2008, 234), y por eso la formación y consolidación de estos espacios intermedios propiamente femeninos de diálogo, exploración y transformación, de un mundo femenino que tenga la capacidad de acoger la diferencia, de integrarla y de transformarse de manera adecuada para que ese espacio sea más rico y más común, constituiría una tarea absolutamente necesaria, imprescindible aun en el caso de que se viviera en una sociedad realmente igualitaria y no cargada de violencia contra las mujeres. De este modo, en una imagen que Zerilli toma prestada de Arendt, se recuperaría el tesoro perdido del feminismo, que no sería otro que el de su libertad política.

\section{Bibliografía}

Arendt, H. (1988), Sobre la revolución, Madrid, Alianza.

Arendt, H. (1990), Hombres en tiempos de oscuridad, Barcelona, Paidós.

11 Por eso se tuvo que recurrir a menudo a lugares improvisados o a otros donde los hombres no transitaban para forjar espacios de sociabilidad femenina, como por ejemplo los lavaderos (vid. Perrot, 1997). Fatima Mernissi (1995), por su parte, ha destacado en el mundo islámico la existencia de espacios de sociabilidad específicamente femenina en torno a figuras como pudieran ser los santos o las santas, dentro de los cuales se respiraba una mayor libertad y se podía hablar de numerosos temas que estaban vedados a las mujeres. 
Arendt, H. (1993), La condición humana, Barcelona, Paidós.

Arendt, H. (1995), De la historia a la acción, Barcelona, Paidós.

Arendt, H. (1996), Entre pasado y futuro, Barcelona, Península.

Arendt, H. (1997a), ¿Qué es la política?, Barcelona, Paidós.

Arendt, H. (1997b), Filosofía y política; Heidegger y el existencialismo, Bilbao, Besatari.

Arendt, H. (2001), El concepto de amor en San Agustín, Madrid, Encuentro.

Arendt, H. (2002), La vida del espíritu, Barcelona, Paidós.

Arendt, H. (2004), La tradición oculta, Barcelona, Paidós.

Arendt, H. (2005a), Ensayos de comprensión, 1930-1954: escritos no reunidos e inéditos de Hannah Arendt. Madrid, Caparrós.

Arendt, H. (2005b), Sobre la violencia, Madrid, Alianza.

Arendt, H. (2006), Diario filosófico: 1950-1973. Barcelona, Herder.

Arendt, H. (2009), Los orígenes del totalitarismo, Madrid, Prisa Innova.

Benhabib, S. (1996), The reluctant modernism of Hannah Arendt, Thousand Oaks, Sage.

Birulés, F. (2007), Una herencia sin testamento: Hannah Arendt, Barcelona, Herder.

Birulés, F. (2009), «Notas sobre Hannah Arendt y los feminismos», Revista Anthropos, ${ }^{\circ}$ 224, pp. 151-157.

Birulés, F. (2013), «Mundo común, feminismo y mitología», Isegoría, Revista de Filosofía Moral y Política, no 49, julio-diciembre 2013, pp. 407-420.

Birulés, F. (2014), Entreactes: entorn de la política, el feminisme i el pensament, Canet de Roselló, Trabucaire.

Butler, J. (2007), El Género en disputa: el feminismo y la subversión de la identidad, Barcelona, Paidós.

Campillo, A. (2002), «Espacios de aparición: el concepto de lo político en Hannah Arendt», Daimon: Revista de filosofía , n 26, pp. 159-186.

Campillo, N. (2013), Hannah Arendt: lo filosófico y lo político, Valencia, Publicacions de la Universitat de València.

Canovan, M. (1992), Hannah Arendt: a reinterpretation of her political thought, Cambridge, Cambridge University Press.

Collin, F. (1999), L'homme est-il devenu superflu : Hannah Arendt, Paris, Jacob.

Duhet, P. M. (1974), Las mujeres y la revolución 1789-1794, Barcelona, Península.

Forti, S. (2001), Vida del espíritu y tiempo de la polis: Hannah Arendt entre filosofía y política, Madrid, Cátedra; Valencia, Universitat de València, Madrid, Instituto de la mujer.

Fraisse, G. (1989), Musa de la razón: la democracia excluyente y la diferencia de los sexos, Madrid, Cátedra; Valencia, Universitat de València, Madrid, Instituto de la mujer.

Fraisse, G. (2003), Los dos gobiernos: la familia y la ciudad, Madrid, Cátedra; Valencia, Universitat de València, Madrid, Instituto de la mujer.

Guerra, M.J. (1999), «Controversias en torno a la recepción crítico-feminista de la obra de Hannah Arendt», Laguna: Revista de Filosofía, no extra 1, pp. 385-394.

Guerra, M.J. (2011), «Arendt y los feminismos contemporáneos: ontología y política», Daimon: Revista de Filosofía, Suplemento 4, pp. 203-212.

Honig, B. (1993), Political theory and the displacement of politics, London, Cornell University Press.

Lefort, C. (1990), La invención democrática, Buenos Aires, Nueva Visión. 
Librería de Mujeres de Milán (2004), No creas tener derechos, Madrid, Horas y Horas.

Mernissi, F. (1995), El poder olvidado, Barcelona, Icaria.

Muraro, L. (2013), Autorità, Torino, Rosenberg \& Sellier.

Negri, T. (1994), El poder constituyente: ensayo sobre las alternativas de la modernidad, Madrid, Libertarias/Prodhufi.

Perrot, M. (1997), Mujeres en la ciudad, Barcelona, Andrés Bello.

Rich, A. (1983), Sobre mentiras, secretos y silencios, Barcelona, Icaria.

Sánchez, C. (2003), Hannah Arendt: el espacio de la política, Madrid, Centro de Estudios Políticos y Constitucionales.

Scott, J.C. (2000), Los dominados y el arte de la resistencia, México DF, Era.

Soja, E. (1989), Postmodern geographies: the reassertion of space in critical social theory, London, Verso.

Zerilli, L. (2003), «Doing without knowing», en: Cressida J. Heyes (Ed.): The Grammar of Politics: Wittgenstein and Political Philosophy, New York, Cornell University Press.

Zerilli, L. (2008), El feminismo y el abismo de la libertad, Buenos Aires, Fondo de Cultura Económica.

Zerilli, L. (2011), «Judici. La facultad de juzgar democráticamente», Taula: Quaderns de Pensament, $\mathrm{n}^{\circ}$ 43, pp. 71-76.

Zizek, S. (2007), En defensa de la intolerancia, Madrid, Sequitur. 